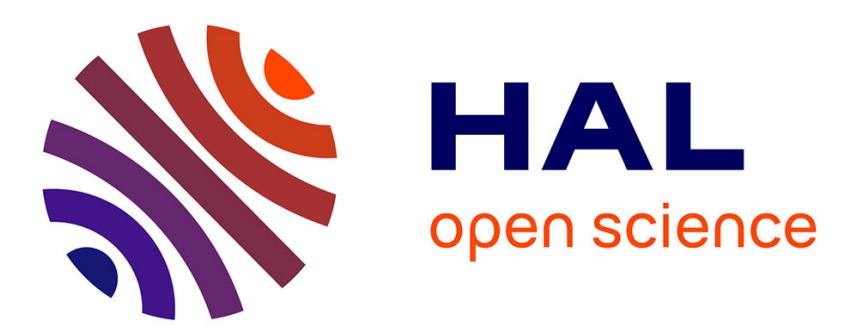

\title{
Economic growth and the transition from non-renewable to renewable energy
}

Alfred Greiner, Lars Grüne, Willi Semmler

\section{To cite this version:}

Alfred Greiner, Lars Grüne, Willi Semmler. Economic growth and the transition from non-renewable to renewable energy. Environment and Development Economics, 2013, 34 p. 10.1017/S1355770X13000491 . hal-00944277

\section{HAL Id: hal-00944277 \\ https://hal.inria.fr/hal-00944277}

Submitted on 10 Feb 2014

HAL is a multi-disciplinary open access archive for the deposit and dissemination of scientific research documents, whether they are published or not. The documents may come from teaching and research institutions in France or abroad, or from public or private research centers.
L'archive ouverte pluridisciplinaire HAL, est destinée au dépôt et à la diffusion de documents scientifiques de niveau recherche, publiés ou non, émanant des établissements d'enseignement et de recherche français ou étrangers, des laboratoires publics ou privés. 


\title{
Economic Growth and the Transition from Non-renewable to Renewable Energy*
}

\author{
Alfred Greiner ${ }^{\dagger} \quad$ Lars Gruene ${ }^{\ddagger} \quad$ Willi Semmler ${ }^{\S}$
}

\begin{abstract}
The paper considers the transition of an economy from non-renewable to renewable energy. The Hotelling theorem suggests to extract a non-renewable resource in an optimal way such that the resource tends to be depleted when optimally extracted. Yet, it might not be reasonable to deplete non-renewable energy sources that create externalities such as $\mathrm{CO}_{2}$ emissions and global warming. The paper sets up a canonical growth model with damages in the household's welfare function and two energy sources - non-renewable and renewable energy. To produce renewable energy a capital stock must be built up. We study when a transition to renewable energy can take place and whether it takes place before non-renewable energy is exhausted. A socially optimal solution is considered that takes into account the negative externality from the non-renewable energy. We also study how the optimal solution can be mimicked in a market economy by policies using subsidies and tax rates. To solve the model version where preferences show a multiplicative effect of consumption and damages from $\mathrm{CO}_{2}$ emission, we use dynamic programming. For a simplified version, with additive arguments in preferences, we use Nonlinear Model Predictive Control to solve the model and study the transition to renewable energy.
\end{abstract}

JEL Codes: Q43, Q54, O13

Keywords: Global warming, renewable energy, economic growth

${ }^{*}$ We are indebted to Anton Bondarev for stimulating discussions and to a referee for helpful comments. Alfred Greiner thanks the Bundesministerium für Bildung und Forschung for financial support (contract 01LA1105C).

${ }^{\dagger}$ Dept. of Business Adm. and Economics, Bielefeld University, agreiner@wiwi.uni-bielefeld.de

${ }^{\ddagger}$ Dept. of Mathematics, University of Bayreuth, lars.gruene@uni-bayreuth.de

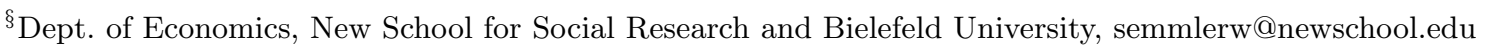




\section{Introduction}

Global warming has become one of the most urgent environmental problems of our time. It is widely acknowledged that anthropogenic emissions of greenhouse gases, in particular $\mathrm{CO}_{2}$, are the cause of a rising greenhouse gas concentration in the atmosphere leading to a changed climate on Earth. As regards global $\mathrm{CO}_{2}$ emissions, empirical research shows that up to 90 percent of $\mathrm{CO}_{2}$ emissions comes from fossil energy related activities (production and use of fossil energy for electricity, for example). Input-output tables clearly demonstrate that the production and use of fossil energy is highly correlated with $\mathrm{CO}_{2}$ emissions, see Mittnik et al. (2010).

In recent economic research on policies against global warming, a large number of studies are concerned with mitigation policies, such as cap \& trade and carbon tax, to combat global warming 1 Yet, another type of studies elaborates on new technologies as solution to global warming. In a number of recent research paper 2 the effort focuses on the transition from fossil energy to renewable energy to reduce $\mathrm{CO}_{2}$ emissions. The use of fossil energy in a market economy creates significant externalities and contributes to $\mathrm{CO}_{2}$ emissions. Green energy that has no such externalities is seen as backstop technology the implementation of which can significantly contribute to the reduction of the causes of global warming. Hence, substituting polluting fossil energy by non-polluting energy could be of great help in alleviating the problem of global warming.

Major substitutes for fossil energy are renewable energy sources such as solar, wind, water, geothermal and biomass energy or atomic energy. However, the Fukushima catastrophe in Japan has illustrated that the use of atomic energy may be associated with extremely high risks. Therefore, developing a more extensive renewable energy sector that substantially reduces $\mathrm{CO}_{2}$ emissions seems to be the more promising route to reduce global warming and its negative effect on welfare of individuals in the long-run. Moreover, renewable energy yields more energy independence and one can move away not only from hazardous nuclear power, but also from the limited non-renewable fossil energy, such as coal and crude oil, the prices of which appear to be rising in the long-run, see Greiner et al. (2012). Thus, the major issue is the question of how such a transition will work for a social optimum solution and whether a laissez-faire economy can

\footnotetext{
${ }^{1}$ See e.g. Nordhaus (2008)

${ }^{2}$ See for example Edenhofer et al. (2011), Heinzel and Winkler (2011), and van der Ploeg and Withagen (2011).
} 
have sufficient incentives to bring about this transition to renewable energy sources. Another issue in this context is whether the non-renewable energy, with the externality of $\mathrm{CO}_{2}$ emissions, will be depleted completely or left partly unexploited and to what extent less $\mathrm{CO}_{2}$ emissions will occur through a transition to renewable energy.

As concerns the appropriateness of renewable energy, Jacobson and Delucchi (2011, 2011a) extensively discuss that source of energy in two contributions. They highlight energy system characteristics of renewable energy sources, current and future energy demand, the availability of resources as well as area and material requirements. In addition, they address the variability, the economics and policy of renewable energy. They estimate that a renewable energy infrastructure would considerably reduce world power demand while only modestly requiring more of the world's land. As a result, they suggest to produce all new energy with renewables by 2030 and to replace the pre-existing energy by 2050. Barriers to that are primarily of social and political nature but not technological or economic since the energy cost in a world with renewable energy should be similar to that today.

In the theoretical economics literature, one can also find contributions that study the use of different sources of energy to produce final output. For example, Hoel and Kverndokk (1996) present a resource model where the use of the resource generates negative externalities. There exists a non-polluting perfect substitute for the polluting resource, with the non-polluting backstop being available at a constant unit cost. Hoel and Kverndokk show, among other things, that it is optimal to extract the polluting resource even when its price is equal to the price of the non-polluting resource. In a more recent contribution, van der Ploeg und Withagen (2011) adopt the model by Hoel and Kverndokk and change two assumptions: They do not allow for a decay of greenhouse gases and they assume that capital must be built up to produce the final output. However, capital is not a perfect substitute for the energy input. Energy is produced using a polluting non-renewable resource and a non-polluting renewable energy source that is available at a constant unit cost, as in Hoel and Kverndokk. They show that it is optimal to use only the polluting resource initially and, later on, only renewables, when the initial stock of the polluting resource is small. The lower the cost of the renewable, the more of the polluting energy source is left in situ and the sooner the only renewable phase starts. When the initial 
stock of the polluting resource is large, it is optimal to first use the polluting resource, then the non-polluting and, finally, the polluting one again. In a different approach van der Ploeg und Withagen (2012) analyze the optimal use of two non-renewable resources with one implying emissions of a great many greenhouse gases (coal) and one source going along with relatively little (oil). It is demonstrated that the sup-optimal market solution uses too much of the more polluting energy source unless the government corrects this market failure.

The models by Hoel and Kverndokk (1996) and by van der Ploeg und Withagen (2011, 2012) have the same structure: There is a polluting resource that can be perfectly substituted by a non-polluting one at a given cost, with both variables being control variables. Thus, their models belong to the general class of models analyzed by Krautkraemer (1998).

In a different class of models, there is a man-made capital stock that can serve as a perfect substitute for the non-renewable resource, as first presented in the model by Krautkraemer (1985). Krautkraemer analyzes a growth model where a polluting resource is used to produce output that can be either consumed or invested. The capital stock can be either an imperfect or a perfect substitute for the polluting resource, the stock of which has an amenity value. Given these assumptions, Krautkraemer demonstrates that the resource will not necessarily be completely exhausted if the initial stock of the man-made capital and the elasticity of substitution between the resource and capital are sufficiently large.

In this contribution, we present a model that combines the two previous approaches. Thus, we assume that energy can be produced either from a non-renewable energy source, such as fossil fuels, or from a renewable source that requires investment in a capital stock, as in Krautkraemer (1985). While the renewable energy does not emit greenhouse gases and, thus, does not contribute to global warming, burning fossil fuels to generate energy raises the greenhouse gas concentration on Earth, thus, generating damages to welfare, as in the contributions by Hoel and Kverndokk (1996) and by van der Ploeg und Withagen (2011, 2012).

Similarly to Greiner et al. (2010), we discuss two versions of the model, one representing the laissez-faire market solution where the external effect of burning fossil fuels is not taken into account by agents, and the other version representing the social planner's solution that allows to choose an optimal allocation of capital to renewable energy so as to counteract the 
damages created by the high $\mathrm{CO}_{2}$ emitting fossil energy sector. We are doing this in a model with preferences, since the long-horizon welfare effects both from reducing the damages from $\mathrm{CO}_{2}$ emissions as well as from technological improvements in energy production can be suitably modeled from this perspective. We also evaluate the effects resulting from differences in private and social rates of time preference as originally assumed in Arrow and Kurz (1970) and analyzed by Heinzel and Winkler (2011) in the context of an environmental model.

As undertaken in Heinzel and Winkler (2011), and van der Ploeg and Withagen (2011, 2012), in our paper here, in contrast to the paper by Greiner et al. (2010), we also let damages, arising from cumulative $\mathrm{CO}_{2}$ emission, affect households' welfare. We present a model version where consumption multiplicatively interacts with damages in the household's welfare function, but also a model variant with additive arguments in the welfare function. We will present analytical solutions for the multiplicative version and report numerical solutions of this variant using dynamic programming (DP). We will use Nonlinear Model Predictive Control (NMPC) for the additive arguments in the welfare function where the latter is derived from the former through some simplifications. Though the NMPC numerical method approximates the infinite time horizon model, with time periods $N$ becoming very large, the NMPC allows one to explore important issues in a model with a small number of periods, for example $N=10$. It also lets us explore if and when it is optimal to phase in a renewable energy source and when it is optimal to phase out the non-renewable resource. We can also explore to what extent it will be optimal to leave a fraction of the non-renewable resource unexploited.

We intend to address the following research questions. First, we want to characterize the optimal fiscal policy, in particular the optimal rate of subsidy for investment in renewable energy. We are also interested in the question of whether differences in the rates of time preference of the social planner and of the representative agent in the laissez-faire economy changes the outcome, or not. Second, we intend to characterize the time paths of the non-renewable resource and of the renewable resource and how those affect cumulative $\mathrm{CO}_{2}$ emissions. Third, we are interested in whether the non-renewable resource is completely used up or whether it is feasible to have someting left in situ?

The remainder of the paper is organized as follows. Section 2 presents the structure of 
our model. Section 3 explores the properties of the socially optimally solutions and section 4 explores the laissez-faire economy and how the socially optimal solution can be reached through appropriate fiscal policies. Section 5 presents the numerical procedures. The numerical results of our study, using DP and NMPC, are summarized in section 6. Section 7, finally, concludes the paper. In the appendix we give some proofs of the propositions.

\section{The economic model}

The total flow of energy output $E$ arises as the sum of energy produced from a non-polluting energy sector, creating $E_{n}$, and from a polluting energy sector, producing the flow of energy, $E_{p}$. The underlying production functions for the production of the two types of energy are:

$$
\begin{aligned}
& E_{p}(t)=A_{p} u(t) \\
& E_{n}(t)=A_{n} K(t)
\end{aligned}
$$

with $u(t)$ the amount of fossil fuels used at tine $t$ to generate energy and $K$ a stock of capital that produces energy using renewable sources of energy such as wind or solar energy and $A_{i}$, $i=p, n$, denote efficiency indices. Total energy $E$ consists of the sum of these two types of energy. Note that production of the final good $Y(t)$ uses energy and is a concave function of energy input 3

$$
Y=A E^{\alpha}=A\left(A_{n} K+A_{p} u\right)^{\alpha}
$$

with $0<\alpha \leq 1, A>0$. Note that energy is a homogeneous good so that modeling the two types as perfect substitutes can be justified.

The stock of non-renewable energy source evolves over time according to the following law of motion:

$$
\dot{R}=-u, R(0)=R_{0}
$$

As far as the accumulation of total capital is concerned, with a constant decay rate of $\delta$, we have the following:

$$
\dot{K}+\delta K=Y-C-a \cdot u, K(0)=K_{0}
$$

\footnotetext{
${ }^{3}$ In the following we delete the time argument $t$ as long as no ambiguity arises.
} 
with $C$ consumption and $a>0$ gives cost of extracting one unit of the non-renewable resource.

The use of the non-renewable resource leads to an increase of greenhouse gases (GHGs), $M$, above its pre-industrial level $M_{o}$. The greenhouse gas concentration evolves according to

$$
\dot{M}=\beta_{1} u-\mu\left(M-\kappa M_{o}\right), M(0)=M_{0} \geq M_{o}
$$

where $\mu \in(0,1)$ is the inverse of the atmospheric lifetime of greenhouse gases and $\beta_{1} \in(0,1)$ gives that part of greenhouse gases that is not taken up by oceans. The parameter $\kappa>1$ captures the fact that greenhouse gas stabilization is possible only at values exceeding the pre-industrial level. The goal is to achieve stabilization at a doubling of GHGs which would imply $\kappa=2$ in our setting.

We should like to point out that $u$ gives that part of emissions that can be controlled by the planer. Consequently, even for $u=0$ the GHG concentration can rise on the transition path, i.e. for $M<\kappa M_{o}$, since other sources emit $\mathrm{CO}_{2}$ that are beyond the influence of the planer. Concretely, one may think of $u$ as emissions generated by fossil power plants to generate electrical power whereas emissions caused by traffic also contributes to global warming.

Our economy is populated by a continuum of homogeneous agents of measure one with each single agent having measure zero so that we can analyze a representative individual. As to the utility function $U$ we use a generalization of the one presented in Byrne (1997) and adopt the following function that is also resorted to in Smulders and Gradus (1996) and in Greiner (2011) for example:

$$
U=\frac{C^{1-\sigma}\left(M-M_{o}\right)^{-\xi(1-\sigma)}-1}{1-\sigma}
$$

The parameter $1 / \sigma>0$ denotes the inter-temporal elasticity of substitution of consumption between two points in time and $\xi>0$ gives the (dis)utility of the greenhouse gas concentration exceeding the pre-industrial level. For $\sigma=1$ the utility function is logarithmic in consumption and pollution. Later, in section 6.2, we will use simplified preferences which are related to $\sigma=1$ in preferences (7).

In order to see the effect of GHGs on the marginal utility of consumption we compute the cross derivative of the utility function which is given by,

$$
\frac{\partial^{2} U}{\partial C \partial M}=-\xi(1-\sigma) C^{-\sigma}\left(M-M_{o}\right)^{-\xi(1-\sigma)-1}>(<) 0 \leftrightarrow 1 / \sigma<(>) 1 .
$$


Equation (77) shows that the marginal utility of consumption declines when GHGs rises if the inter-temporal elasticity of substitution is larger one. If the inter-temporal elasticity of substitution is smaller one, the negative effect of an additional unit of GHGs is the smaller than the higher consumption. The latter means that a rise in consumption reduces the negative effect of pollution at the margin.

Equation (8) suggests that consumption and a clean environment are complementary for $1 / \sigma>1$ because, in this case, marginal utility of consumption rises with a decline in the level of GHGs. This means that marginal utility of consumption is the higher, the cleaner the environment is. For $1 / \sigma<1$, consumption and GHGs can be considered as substitutes because the marginal (dis)utility of additional pollution declines with a rising level of consumption.

In the next section we first derive the solution of the social planner's problem.

\section{The socially optimal solution}

We can look for the solution of the allocation problem faced by a benevolent social planner taking into consideration the accumulation of greenhouse gases, equation (66). Thus, we have for the planning version the following optimization problem:

$$
\begin{aligned}
\text { Choose }\{C, u\}_{t=0}^{\infty} \quad \text { to maximize } & \int_{0}^{\infty} e^{-\rho t}\left(\frac{C^{1-\sigma}\left(M-M_{o}\right)^{-\xi(1-\sigma)}-1}{1-\sigma}\right) d t \\
\text { subject to: } \quad & (101),(2),(3) \\
& \dot{K}=Y-C-\delta K-a \cdot u \\
& \dot{R}=-u \\
& \dot{M}=\beta_{1} u-\mu\left(M-\kappa M_{o}\right) \\
& R(0)=R_{0}, K(0)=K_{0}, M(0)=M_{0} \geq M_{o} \text { given } \\
& \lim _{t \rightarrow \infty} e^{-\rho t} K(t) \geq 0, \lim _{t \rightarrow \infty} R(t) \geq 0, \lim _{t \rightarrow \infty} M(t) \geq M_{o}
\end{aligned}
$$




\subsection{Optimality conditions}

To find the optimal solution we set up the current-value Hamiltonian function that is written as,

$$
\begin{aligned}
H(\cdot)= & \left(C^{1-\sigma}\left(M-M_{o}\right)^{-\xi(1-\sigma)}-1\right) /(1-\sigma)+\lambda_{1}\left(A\left(A_{p} u+A_{n} K\right)^{\alpha}-C-a u-\delta K\right)+ \\
& \lambda_{2}(-u)+\lambda_{3}\left(\beta_{1} u-\mu\left(M-\kappa M_{o}\right)\right)
\end{aligned}
$$

with $\lambda_{i}, i=1,2,3$, the shadow prices of capital, fossil energy and GHG concentration, respectively. Necessary optimality conditions are:

$$
\begin{aligned}
\frac{\partial H(\cdot)}{\partial C}=0 & \leftrightarrow \quad C=\lambda_{1}^{-1 / \sigma}\left(M-M_{o}\right)^{-\xi(1-\sigma) / \sigma} \\
\frac{\partial H(\cdot)}{\partial u}=0 & \leftrightarrow \quad u=\left(\frac{\lambda_{1}}{\lambda_{2}-\lambda_{3} \beta_{1}+a \lambda_{1}}\right)^{1 /(1-\alpha)} A_{p}^{\alpha /(1-\alpha)}(A \alpha)^{1 /(1-\alpha)}-\frac{A_{n} K}{A_{p}} \\
\dot{\lambda}_{1}=\rho \lambda_{1}-\frac{\partial H(\cdot)}{\partial K} & \leftrightarrow \dot{\lambda}_{1}=(\rho+\delta) \lambda_{1}-\lambda_{1} \alpha A A_{n}\left(A_{n} K+A_{p} u\right)^{\alpha-1} \\
\dot{\lambda}_{2}=\rho \lambda_{2}-\frac{\partial H(\cdot)}{\partial R} & \leftrightarrow \dot{\lambda}_{2}=\rho \lambda_{2} \\
\dot{\lambda}_{3}=\rho \lambda_{3}-\frac{\partial H(\cdot)}{\partial M} & \leftrightarrow \dot{\lambda}_{3}=(\rho+\mu) \lambda_{3}+\xi\left(M-M_{o}\right)^{-\xi(1-\sigma)-1} C^{1-\sigma}
\end{aligned}
$$

Equation (16) shows that the shadow price of the non-renewable energy source exponentially changes at the rate $\rho$, i.e. $\lambda_{2}(t)=\lambda_{2}(0) \cdot e^{\rho t}$, giving the Hotelling rule. The shadow price of capital, $\lambda_{1}$, is positive while that of GHGs, $\lambda_{3}$, is negative since GHGs above the pre-industrial level, to which we limit our considerations, lead to welfare losses.

The extraction rate $u$ will be positive only if the marginal product of $u$ in energy production exceeds its cost which consist of the unit extraction cost, $a$, plus its price relative to the shadow price of capital, $\left(\lambda_{2}-\lambda_{3} \beta_{1}\right) / \lambda_{1}$. It should be noted that the price of the resource consists of the shadow price of the resource, $\lambda_{2}$, plus the effective price of GHGs, $-\lambda_{3} \beta_{1}$, where effective means that the shadow price of GHGs must be multiplied by, $\beta_{1}$, since only $0<\beta_{1}<1$ of GHG emissions enter the atmosphere while the rest is absorbed by oceans.

It must also be pointed out that the marginal product of $u$, of the non-renewable resource used for producing energy, is bounded by above. The marginal product of $u$ is given by $\partial Y / \partial u=$ $A \alpha A_{p}\left(A_{n} K\right)^{\alpha-1}<\infty$, for $u=0$ and $K>0$. That demonstrates that a high capital stock 
to produce renewable energy, $K$, and a low value of $A_{p}$, reflecting the efficiency of the nonrenewable in energy production, tend to reduce the extraction rate. In the extreme case of $A_{p}=0$, the marginal product of $u$ vanishes and there are only costs left resulting from the use of the non-renewable resource. Thus, for a sufficiently low value of $A_{p}$ the resource will not be extracted and the representative agent will only use renewable energy. In that case, the shadow price of the resource will be negative. That holds because the steady state shadow price 4 is $\lambda_{2}^{\star}=-\lambda_{1}^{\star} a+\lambda_{3}^{\star} \beta_{1}<0$, for $A_{p}=0$, and because of equation (16).

On the other hand, if the cost of investment in the renewable energy capital stock is large there may be a time period when investment equals zero and only the polluting resource is used to generate energy. This will occur when the cost of resource extraction is low relative to investment in renewable energy which can be the case for small extraction costs and for small marginal damages of GHGs while productivity of the non-polluting energy capital is low.

From equation (13) the growth rate of consumption can be derived as,

$$
\frac{\dot{C}}{C}=-\frac{1}{\sigma} \frac{\dot{\lambda}_{1}}{\lambda_{1}}-\xi \frac{1-\sigma}{\sigma} \frac{\dot{M}}{M-M_{o}}
$$

That equation demonstrates that on the transition path the growth rate of consumption is higher if consumption and damages from global warming are substitutes compared to the case when consumption and damages are complements, for a given growth rate of the shadow price of capital. This holds because the planner will put a higher weight on raising consumption when GHGs increase since the negative impact of a higher GHG concentration on welfare can be alleviated by higher consumption. If consumption and damages from global warming are complementary the reverse holds. Then, the marginal increase in welfare due to higher consumption is the higher the lower the GHG concentration and the planner will put less weight raising consumption in such a world.

It should also be pointed out that the current-value Hamiltonian is strictly concave in its control variables but not necessarily in the control and state variables jointly and the maximized Hamiltonian is also not necessarily concave in the state variables. Therefore, the necessary conditions are not sufficient for a maximum and they only describe a candidate for the optimum.

\footnotetext{
${ }^{4}$ See the next subsection for details. The ${ }^{\star}$ denotes steady state values.
} 


\subsection{The steady state}

To get insight into the long-run behavior of our model we study its asymptotic behavior where the time derivatives of economic variables equal zero. From equation (4) we know that $u^{\star}=0$ must hold in the long-run because the resource is finite. A zero long-run extraction rate implies that GHGs are obtained as $M^{\star}=\kappa M_{o}$. From $\dot{C}=0$ we obtain

$$
K^{\star}=(A /(\rho+\delta))^{1 /(1-\alpha)} \alpha^{1 /(1-\alpha)} A_{n}^{\alpha /(1-\alpha)}
$$

where we used $u^{\star}=0$. Finally, setting $\dot{K}=0$ leads to

$$
C^{\star}=(\rho+\delta(1-\alpha)) A_{n}^{\alpha /(1-\alpha)}(A /(\rho+\delta))^{1 /(1-\alpha)} \alpha^{\alpha /(1-\alpha)} .
$$

The steady state shadow prices are obtained as follows. Setting $\dot{\lambda}_{3}=0$ and using $M^{\star}=\kappa M_{o}$ gives for the shadow price of GHGs $\lambda_{3}^{\star}=(-\xi)\left(C^{\star}\right)^{1-\sigma}\left(M_{o}(\kappa-1)\right)^{-\xi(1-\sigma)-1} /(\rho+\mu)$ and from equation (13) we obtain for the shadow price of capital $\lambda_{1}^{\star}=\left(C^{\star}\right)^{-\sigma}\left(M_{o}(\kappa-1)\right)^{-\xi(1-\sigma)}$. The steady state shadow price of the resource is obtained as $\lambda_{2}^{\star}=\lambda_{1}^{\star}\left(A \alpha A_{p}\left(A_{n} K^{\star}\right)^{\alpha-1}-a\right)+\lambda_{3}^{\star} \beta_{1}$ from $u^{\star}=0$.

The shadow price of GHGs is negative for $\kappa>1$, which implies that the steady state GHG concentration exceeds the pre-industrial level to which we will confine our analysis since this is the more relevant case. In that case the shadow price of the capital stock used to produce nonpolluting renewable energy is positive at the steady state. Finally, the steady state shadow price of the exhaustible resource, $\lambda_{2}^{\star}$, is positive if the marginal product of the resource at the steady state exceeds unit extraction costs, $a$, plus the effective shadow price of GHGs relative to the shadow price of capital, $-\lambda_{3}^{\star} \beta_{1} / \lambda_{1}$. However, the steady state shadow price of the non-renewable resource may also become negative if the marginal product of the non-renewable energy is small relative to the marginal product of the renewable energy.

\section{The laissez-faire solution and optimal fiscal policy}

Above we have studied the optimization problem who chooses consumption and the optimal rate of extraction for the non-renewable resource considering damages resulting from turning this resource into energy that increases the greenhouse gas concentration. In the laissez-faire 
economy the agent will not internalize the carbon damage inflicted on the environment, since this is an externality, unless the government sets correct incentives to do so.

\subsection{Laissez-faire solution}

Therefore, finding a decentralized allocation path in our economy amounts to solve the following problem:

$$
\begin{aligned}
\text { Choose }\{C, u\}_{t=0}^{\infty} \quad \text { to maximize } & \int_{0}^{\infty} e^{-\rho_{k} t}\left(\frac{C^{1-\sigma}\left(M-M_{o}\right)^{-\xi(1-\sigma)}-1}{1-\sigma}\right) d t \\
\text { subject to: } \quad & (11),(2),(3) \\
& \dot{K}=Y-C-\delta K-a u-\tau u-\Gamma+\theta \dot{K} \\
& \dot{R}=-u \\
& K(0)=K_{0}, M(0)=M_{0} \text { given } \\
& \lim _{t \rightarrow \infty} e^{-\rho_{k} t} K(t) \geq 0, \lim _{t \rightarrow \infty} M(t) \geq M_{o}
\end{aligned}
$$

Before we analyze the outcome of the market solution we want to note some differences to the optimization problem of the social planner. First, the rate of time preference of the agent in the laissez-faire economy, denoted by $\rho_{k}$, need not coincide with that of the social planner. Second, we assume that a government levies a tax $\tau>0$ per unit of extraction of the resource as well as a lump-sum tax $\Gamma$ that may be positive or negative, the latter implying that the government pays transfers to the household. In addition, the government may subsidize investment in capital to foster the formation of renewable energy production by paying $\theta \in(0,1)$ units of output per gross investment $\dot{K}$.

Again, we form the current-value Hamiltonian which now is,

$$
\begin{aligned}
H(\cdot)= & \left(C^{1-\sigma}\left(M-M_{o}\right)^{-\xi(1-\sigma)}-1\right) /(1-\sigma)+ \\
& \gamma_{1}\left(A\left(A_{p} u+A_{n} K\right)^{\alpha}-C-(a+\tau) u-\delta K-\Gamma\right) /(1-\theta)+\gamma_{2}(-u),
\end{aligned}
$$

with $\gamma_{i}, i=1,2$, the shadow prices of capital and of the exhaustible resource, respectively. 
Necessary optimality conditions are given by the following equations:

$$
\begin{aligned}
\frac{\partial H(\cdot)}{\partial C}=0 & \leftrightarrow C=\gamma_{1}^{-1 / \sigma}\left(M-M_{o}\right)^{-\xi(1-\sigma) / \sigma} \\
\frac{\partial H(\cdot)}{\partial u}=0 & \leftrightarrow \quad u=\left(\frac{\gamma_{1}}{\gamma_{2}(1-\theta)+(a+\tau) \gamma_{1}}\right)^{1 /(1-\alpha)}\left(A_{p}^{\alpha} A \alpha\right)^{1 /(1-\alpha)}-\frac{A_{n} K}{A_{p}} \\
\dot{\gamma}_{1}=\rho_{k} \gamma_{1}-\frac{\partial H(\cdot)}{\partial K} & \leftrightarrow \dot{\gamma}_{1}=\left(\rho_{k}+\delta\right) \gamma_{1}-\gamma_{1} \alpha A A_{n}\left(A_{n} K+A_{p} u\right)^{\alpha-1} /(1-\theta) \\
\dot{\gamma}_{2}=\rho_{k} \gamma_{2}-\frac{\partial H(\cdot)}{\partial R} & \leftrightarrow \dot{\gamma}_{2}=\rho_{k} \gamma_{2}
\end{aligned}
$$

Since the evolution of GHGs is taken as given the necessary conditions are also sufficient for an optimum in the market economy if the transversality condition $\lim _{t \rightarrow \infty} e^{-\rho_{k} t}(K(t)+M(t))=0$ is fulfilled.

In the long-run, the social optimum and the market economy do not differ if the rates of time preference of the social planner and of the agent in the market economy are the same which is formally stated in proposition 1 .

Proposition 1. For identical rates of time preference, the steady state of the social optimum coincides with that of the market economy without government intervention. If the time preference in the social optimum exceeds that of the market economy, capital, output and consumption in the social optimum are higher than in the market economy.

Proof: See Appendix.

Proposition 1 makes clear that in the long-run both versions of the model yield the same outcome, unless the rates of time preference differ. It is true that the representative agent in the market economy only takes into account the private costs of the resource extraction and neglects the social costs resulting from the emission of GHGs since his influence is negligible. However, since he knows that the resource is finite he invests in the renewable energy capital stock. Further, since resource extraction equals zero in the long-run the difference between the social optimum and the market economy vanishes, provided the rate of time preference in the market economy is the same as in the social optimum. If the rate of time preference in the social optimum is smaller than in the competitive market economy it will yield higher steady state capital and, thus, output as well as higher consumption and, therefore, also higher welfare. 
But it is obvious that the competitive market economy and the social optimum do not coincide along the transition path unless the government corrects market failures. For example, comparing (14) with (23) suggests that the extraction of the polluting resource is expected to be higher in the laissez-faire economy without government intervention than in the social optimum solution. That holds because in the social optimum the price of emitting GHGs, given by $-\lambda_{3} \beta_{1}$, is taken into account which is not the case in the market economy. In the latter, the cost of emitting GHGs is neglected because this is an externality that is not considered by the households, unless the government intervenes and levies a tax on the use of non-renewable energy that generates the GHG emissions. In the next subsection we study how the fiscal parameters must be set such that the market economy will replicate the social optimum solution.

\subsection{Optimal fiscal policy}

To derive optimal tax rates and the optimal investment subsidy we will first assume that the rate of time preference of the social planner coincides with that of the representative agent in the market economy. Proposition 2 demonstrates how fiscal policy parameters must be set in this case.

Proposition 2. Assume that $\rho=\rho_{k}$ holds. Then, the market economy replicates the social optimum if and only if $\theta=\theta^{o}, \tau=\tau^{o}$ and $\Gamma=\Gamma^{o}$ holds, with

$$
\theta^{o}=0, \tau^{o}=-\lambda_{3} \beta_{1} / \lambda_{1}, \quad \Gamma^{o}=\lambda_{3} \beta_{1} u / \lambda_{1} \text { for all } t \in[0, \infty)
$$

Proof: See Appendix.

This proposition shows that the optimal subsidy for investment in non-renewable energy equals zero. The reason is that the marginal product of capital to produce non-polluting energy is the same in both versions of the model so that the shadow price of capital in the social optimum follows the same path as in the market economy, provided the evolution of capital and extraction of the non-renewable resource is the same. The latter is achieved by a tax on unit extraction $u$ where the optimal tax equals the effective price of GHGs, $-\lambda_{3} \beta_{1}$, divided by the shadow price of capital, $\lambda_{1} 5$ This shows that in the case resource extraction is taxed an additional subsidy for

\footnotetext{
${ }^{5}$ Recall that the shadow price of GHGs $\lambda_{3}$ is negative.
} 
renewable energy would lead to over-investment in the renewable energy capital stock such that the stock of capital would grow too fast compared to the social optimum. Finally, lump-sum taxes $\Gamma$ are negative implying that the tax revenue from taxing resource extraction must be redistributed in a lump-sum way to the private sector. This guarantees that the evolution of the capital stock in both versions is identical and also assures that the budget of the government is balanced.

It should also be noted that the optimal tax rate is independent of the shadow price of the resource. It only depends on the effective shadow price of GHG concentration and on the shadow price of the non-polluting energy source, i.e. on the shadow price of the capital stock. The higher the marginal damage of an additional unit of GHGs in the atmosphere and the lower the shadow price of the non-polluting energy technology, the higher the optimal tax rate on the extraction of the polluting resource will be.

If the rate of time preference of the social planner exceeds the one of agents in the market economy, the optimal fiscal parameters take different values. Proposition 3 gives the result for this case.

Proposition 3. Assume that $\Delta \rho:=\rho_{k}-\rho>0$ holds. Then, the market economy replicates the social optimum if and only if $\theta=\theta^{\circ}, \tau=\tau^{o}$ and $\Gamma=\Gamma^{o}$ holds, with

$$
\theta^{o}=\frac{\Delta \rho}{\Delta \rho+Y_{K}}, \tau^{o}=\left(\frac{\lambda_{2}}{\lambda_{1}}\right)\left(\frac{\Delta \rho}{\Delta \rho+Y_{K}}\right)-\frac{\lambda_{3} \beta_{1}}{\lambda_{1}}, \quad \Gamma^{o}=\theta^{o} \dot{K}-\tau^{o} u \text { for all } t \in[0, \infty)
$$

where $Y_{K}=\partial Y / \partial K$.

Proof: See Appendix.

Proposition 3 demonstrates that a subsidy for renewable energy is necessary to replicate the social optimum if the time preference of the social planner is larger than that of the agents in the market economy. This holds because even if the evolution of capital and the extraction rate were the same, the shadow prices in the two versions would be different due to the difference in the rate of time preference. Hence, the subsidy is to compensate for the difference in the rates of time preference where the optimal subsidy is given by the difference in the time preference divided by the marginal product of capital plus that difference. Then, the shadow price of capital 
in the market economy evolves at the same pace as in the social optimum if the extraction rate and the stock of capital are also the same in the two versions.

To equate extraction rates one can again use the optimality condition for that variable in the two versions of the model and set the tax rate on extraction such that equality of $u$ is obtained. This is achieved when the tax rate equals the investment subsidy multiplied by the shadow price of the resource in the social optimum, $\theta^{\circ} \lambda_{2}$, plus the effective price of GHGs, $-\lambda_{3} \beta_{1}$, divided by the shadow price of capital, $\lambda_{1}$. The lump-sum payment now is a lump-sum tax and is obtained by equating the evolution of capital in the two versions of the model. Doing so shows that the tax revenue consisting of the lump-sum tax, $\Gamma$, plus the revenue from taxing resource extraction, $\tau u$, just equals the subsidies, $\theta \dot{K}$, which gives the budget constraint of the government.

In case the rates of time preference differ the optimal tax rate also depends on the shadow price of the resource in the social optimum, besides the shadow price of GHGs and the shadow price of capital. In general, the optimal tax rate on extraction will be the higher, the higher the shadow price of the resource, the lower the marginal product of the renewable energy technology and the higher the difference in the rate of time preference of the social planner and of the agents in the market economy.

\section{Numerical procedures}

For the numerical solution of the optimal control problem we employ two different procedures. On the one hand, we use a dynamic programming (DP) approach. The DP method has the advantage that a global solution to the optimal control problem can be found, by first computing an approximation to the optimal value function $V$ and then the optimal control, and its time path, is computed from $V$. For a detailed description of the specific DP algorithm we are using we refer to Gruene and Semmler (2004).

The main disadvantage of DP is that its numerical effort typically grows exponentially with the dimension of the state variable. Hence, even for moderate state dimensions it may be impossible to compute a solution with reasonable accuracy. A remedy to this problem can be obtained by using nonlinear model predictive control (NMPC), which is the second method we use in this paper. Instead of computing the optimal value function for all possible initial states, 
NMPC only computes single (approximate) optimal trajectories.

In order to describe the method, let us abstractly write the optimal control problem as

$$
\operatorname{maximize} \quad \int_{0}^{\infty} e^{-\rho t} \ell(x(t), u(t)) d t,
$$

where $x(t)$ satisfies $\dot{x}(t)=f(x(t), u(t)), x(0)=x_{0}$ and the maximization takes place over a set of admissible control functions. By discretizing this problem in time, we obtain an approximate discrete time problem of the form

$$
\text { maximize } \sum_{i=0}^{\infty} \beta^{i} \ell\left(x_{i}, u_{i}\right),
$$

where the maximization is now performed over a sequence $u_{i}$ of control values and the sequence $x_{i}$ satisfies $x_{i+1}=\Phi\left(h, x_{i}, u_{i}\right)$, Here $h>0$ is the discretization time step, $\beta=e^{-\rho h}$ and $\Phi$ is a numerical scheme approximating the solution of $\dot{x}(t)=f(x(t), u(t))$ on the time interval $[i h,(i+1) h]$. For details and references in which the error of this discretization is analyzed we refer to Section 2.2 of Gruene and Semmler (2004).

The idea of NMPC now lies in replacing the maximization of the infinite horizon functional (26) by the iterative maximization of finite horizon functionals

$$
\operatorname{maximize} \sum_{k=0}^{N} \beta^{i} \ell\left(x_{k, i}, u_{k, i}\right),
$$

for a truncated finite horizon $N \in \mathbb{N}$ with $x_{k+1, i}=\Phi\left(h, x_{k, i}, u_{k, i}\right)$ and the index $i$ indicates the number of the iteration, cf. the algorithm below. Note that neither $\beta$ nor $\ell$ nor $\Phi$ changes when passing from (26) to (27), only the optimization horizon is truncated.

Problems of type (27) can be efficiently solved numerically by converting them into a static nonlinear program and solving them by efficient NLP solvers, see Gruene and Pannek (2012). In our simulations, we have used a discounted variant of the MATLAB routine nmpc.m available from www.nmpc-book.com, which uses MATLAB's fmincon NLP solver in order to solve the resulting static optimization problem.

Given an initial value $x_{0}$, an approximate solution of (26) can now be obtained by iteratively solving (27) as follows:

(1) for $i=1,2,3, \ldots$

(2) solve (27) with initial value $x_{0, i}:=x_{i}$ and denote the 
resulting optimal control sequence by $u_{k, i}^{*}$

(3) $\quad$ set $u_{i}:=u_{0, i}^{*}$ and $x_{i+1}:=\Phi\left(h, x_{i}, u_{i}\right)$

(4) end of for-loop

This algorithm yields an infinite trajectory $x_{i}, i=1,2,3, \ldots$ whose control sequence $u_{i}$ consists of all the first elements $u_{0, i}^{*}$ of the optimal control sequences for the finite horizon subproblems (27).

Under appropriate assumptions on the problem, it can be shown that the solution $\left(x_{i}, u_{i}\right)$ (which depends on the choice of $N$ in (27) ) converges to the optimal solution of (26) as $N \rightarrow \infty$. The main requirement in these assumptions is the existence of an optimal equilibrium for the infinite horizon problem (26). If this equilibrium is known it can be used as an additional constraint in (27) in order to improve the convergence properties, see Angeli, Amrit and Rawlings (2012). However, recent results have shown that without a priori knowledge of this equilibrium this convergence can also be ensured, see Gruene (2012), and this is the approach we use in the computations in this paper.

\section{Numerical results}

Next we report numerical solutions using DP, which gives us the infinite horizon solution for each initial conditions in a three dimensional space. We also use NMPC as approximation method. If $\sigma$ is different from unity, the two arguments in the preferences are multiplicatively connected. For this model version we use for $\sigma>1$ the infinite horizon DP as numerical method. For a model version with a simplified welfare function, which gives us additive arguments in the welfare function 6 we use NMPC. This algorithm, as approximation method for DP, appears to be more realistic and practical in an economic context. It is more appropriate for the economic issues at hand and lets us observe directly the state as well as the decision variables. It allows us also to explore the solution paths for various initial conditions in a finite time horizon context as approximation for the infinite horizon problem.

In the numerical analysis below we set $\mu=0.1$ and $\beta_{1}=0.5$ as plausible values and $\kappa=2$,

\footnotetext{
${ }^{6}$ The simplified preferences we use here are closely related to preferences when $\sigma$ approaches unity.
} 
$M(0)=M_{o}$ with $M_{o}=1$. Other reasonable parameters are: $\rho=0.03$ and $\delta=0.05, \alpha=0.5$, $A=1, A_{n}=1, a=0.1, \xi=0.5$. We take a rather large $A_{p}$, namely $A_{p}=1000$, which gives rise to reasonable steady state results. From an economic point of view this makes sense since $A_{n}$ is the parameter for a stock and $A_{p}$ a parameter for a flow. Also, as the computations of the steady state values have shown, only a very large $A_{p}$ allows for a steady state where the shadow price of the non-renewable energy source is non-negative.

\subsection{DP results}

For DP as the solution method we take the above parameters and employ preferences as expressed in equation (7) with $\sigma=1.1$.

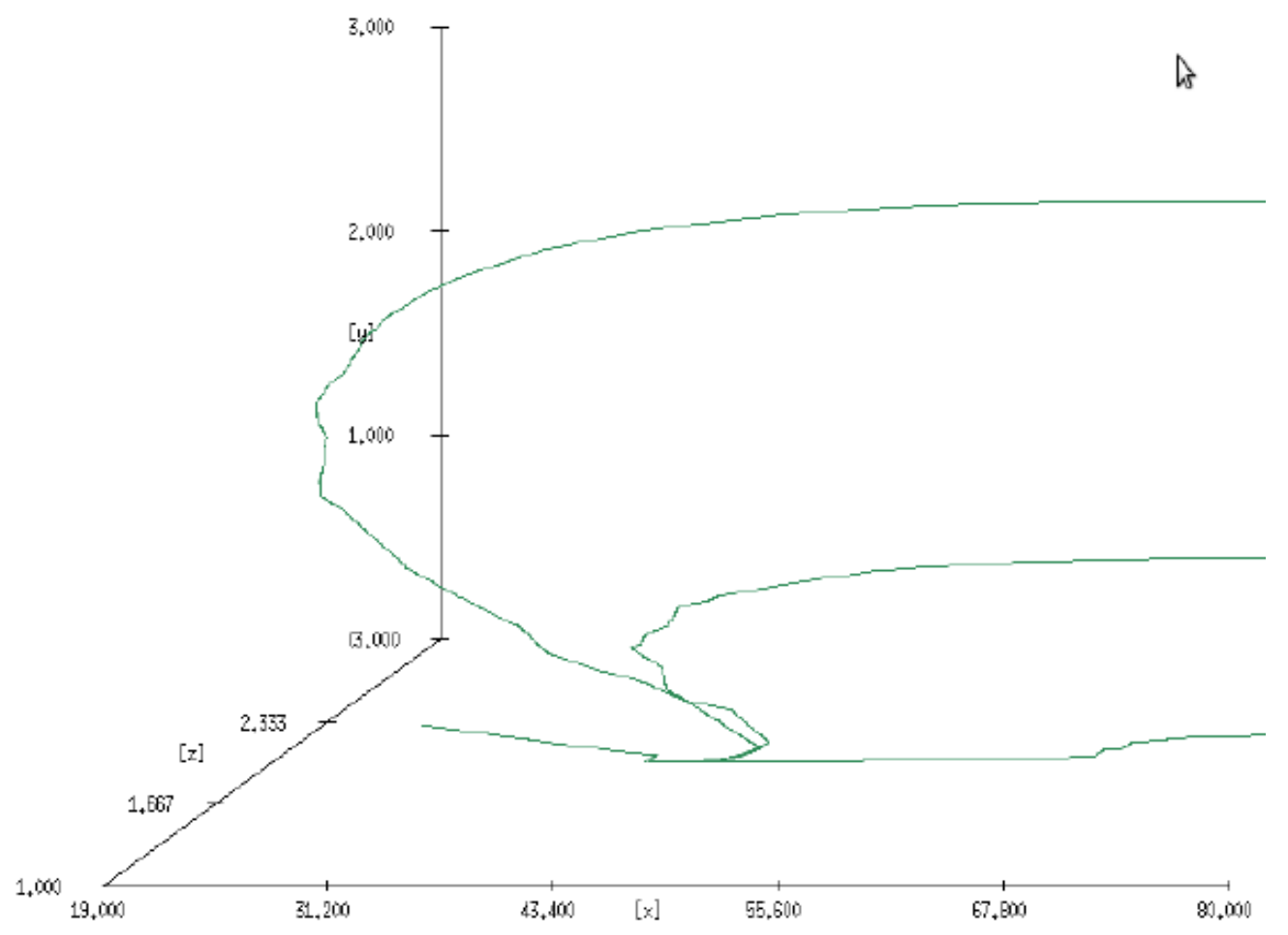

Figure 1: Trajectories with DP for different initial $K(0)$ and $\mathrm{R}(0), \sigma=1.1, M(0)=\kappa M_{0}=2$

Figure 1 shows trajectories using DP. We observe for example for initial values $K(0)=37.0$ and $R(0)=2.95$ a convergence to $K^{*}=39.2$, to $R^{*}=0.002$ (upper left graph). For $K(0)=37.0$, and $R(0)=0.1$ the trajectories converge to $K^{*}=39.2$, and to $R^{*}=0.004$ (lower left graph). Note that we have always set $M(0)=\kappa M_{0}=2$, to its steady state value, to show the dynamics 
in the $K-R$ plane.

Next, in figure 2 we show the shape of the value function obtained by DP.

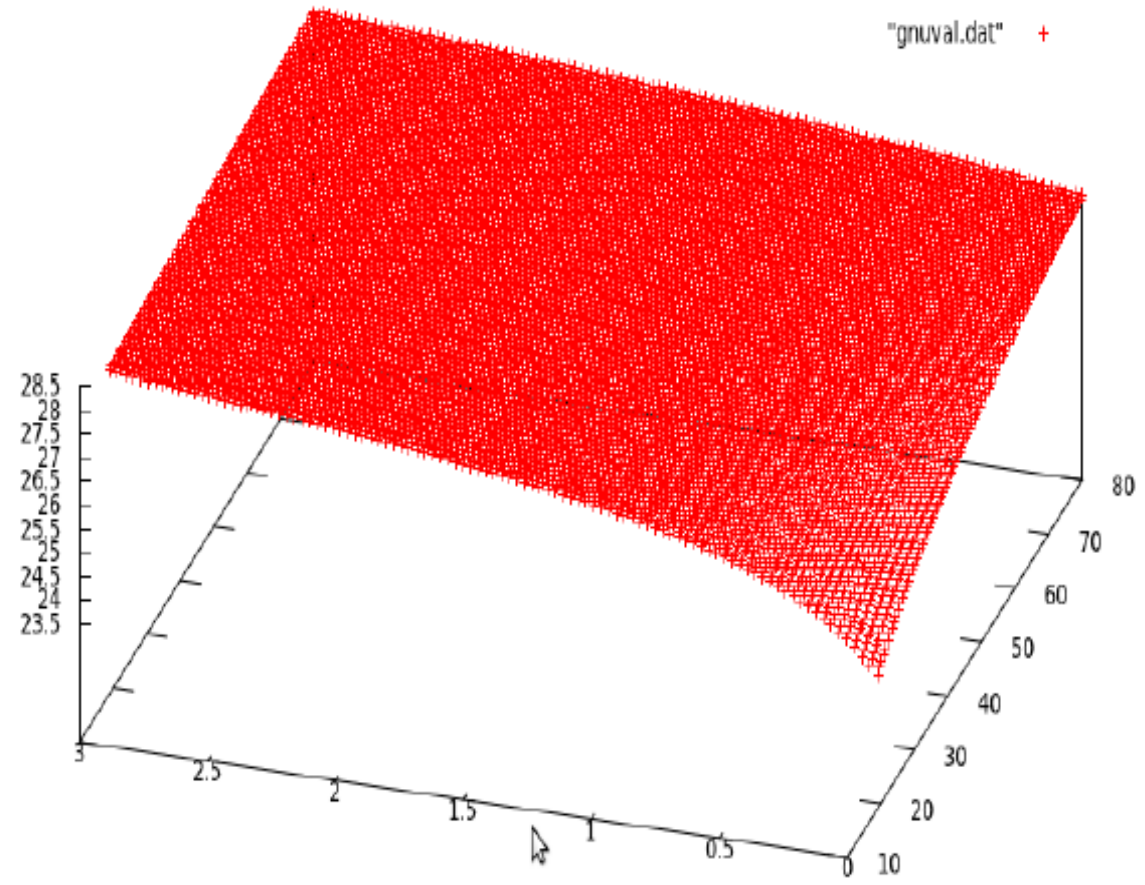

Figure 2: Value function computed with DP corresponding to figure 1, $\sigma=1.1$

The value function is computed on a grid of the state and control variables. Thus, the solution paths of the state and control variables can be obtained at any point in the state space. As the value function in figure 2 , shown in the $K-R$ plane, demonstrates, with a lower initial fossil resource $R$, but also lower $K$, welfare is lower. Apparently lower $R$ also means lower energy, lower output and lower consumption. The reduced externalities from the lower $R(0)$ do not seem to compensate the lower consumption from the output of the low energy economy, so that overall the welfare is lower than somewhere else in the state space.

As stated above, we could show that the dynamics of the model are expected to become unstable if $A_{p}$ is small. We have also replicated this result by using DP, which showed that trajectories with initial value of $K(0)=37.0$, for $R(0)$ initial conditions, ranging from $R(0)=$ 2.95 , and to $R(0)=0.004$ will be unstable for small $A_{p}$. So, all trajectories moved to the right, indicating instability for the model with low productivity of fossil fuel energy. In those cases no 
non-renewable energy is extracted and only capital stock for the production of renewable energy is built up.

\subsection{Results from NMPC}

The following are the results from NMPC as the solution method, using additive preferences 7 We employ here a simplified welfare function of equation (7) in section 3 . We use:

$$
U=\ln (C)-\gamma\left(M-M_{o}\right)^{2}
$$

instead of (7). Setting $\sigma=1$ gives $U=\ln (C)-\xi \ln \left(M-M_{o}\right)$ which would imply that damages are a convex function of GHGs exceeding the pre-industrial level $M_{o}$. However, since a concave shape is more realistic we replace the damages $-\xi \ln \left(M-M_{o}\right)$ by $-\gamma\left(M-M_{o}\right)^{2}$. Another reason for the use of a more simplified welfare function in the NMPC procedure is that in NMPC a high dimensional differential equation system has to be solved which is quite time consuming with the MATLAB optimization solver. The NMPC works much faster for additively separable preferences (28) than for the multiplicative form of equation (7). The qualitative results are expected to be similar.

Except for the above revised form of preferences, we use the same parameters as in section 6.1.

\footnotetext{
${ }^{7}$ For a solution of a growth and climate change model using Nonlinear Model Prodictive Control see, for example, Brechet et al. (2012).
} 


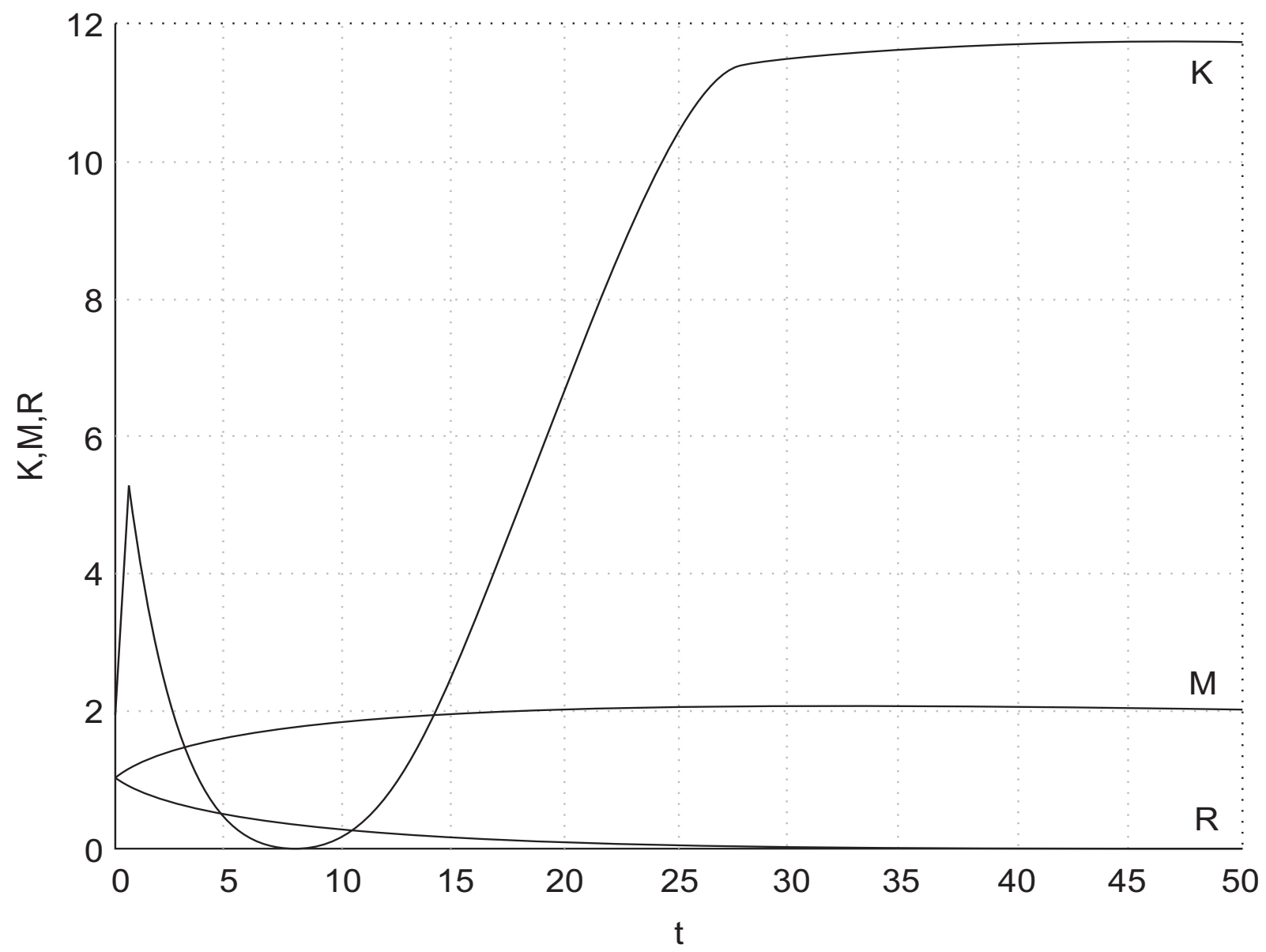

Figure 3: NMPC results with $R(0)=1, K(0)=1, M(0)=1, N=8$

In figure 3, the upper $\mathrm{U}$ shaped graph, first quickly rising but then going to zero, and eventually rising to a higher level, is the capital stock, used for the production of renewable energy. Since there is sufficient non-renewable energy in deposits, it is optimal to let the capital stock go to zero and then, when the non-renewable energy tends to be exhausted, it is optimal to build up the capital stock to a high level. A high capital stock to produce renewable energy is required, because apparently the created externalities through the use of non-renewable energy sources have become too high and too costly.

The negative externalities and damaging effects are indicated in figure 3 through the middle graph, representing $M(t)$, the cumulative $\mathrm{CO}_{2}$ emission, which of course tends to 2 as the previous numerical solutions using DP already demonstrated. The lower graph, which is monotonically decreasing, represents the fate of the non-renewable resource $R_{t}$. 
The next example is for a different initial condition for $R$, we take $R(0)=0.5$, but we keep the same parameters as before.

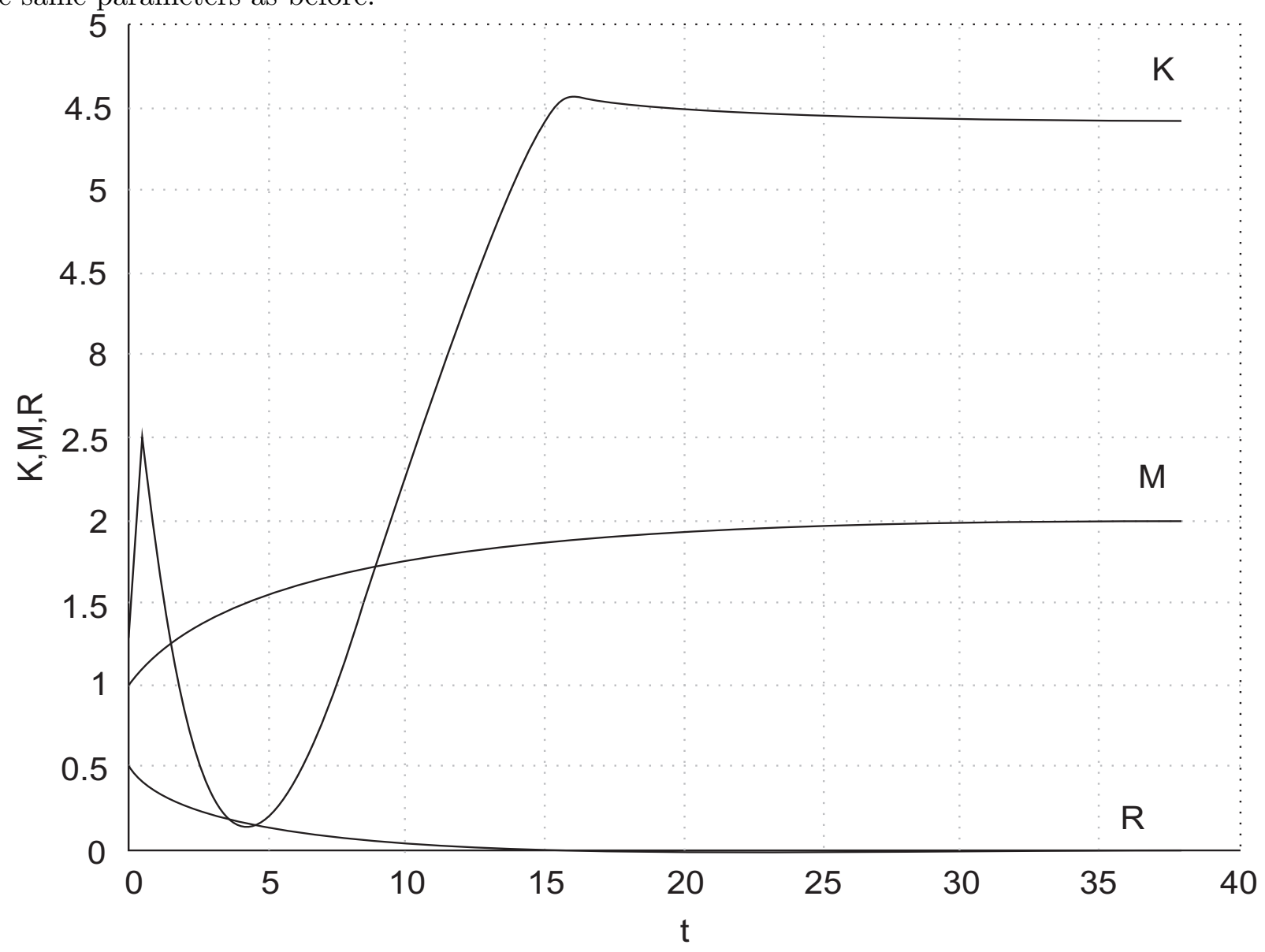

Figure 4: NMPC results for $R(0)=0.5, K(0)=1, M(0)=1, N=8$

In figure 4 too, the capital stock first declines but then rises to a high level, once nonrenewable energy is exhausted and the cumulative externalities have been piled up. However, since initial non-renewable resources are low, it is not optimal to reduce capital to zero for some time and rely only on non-renewable energy production alone. The results also show that with a low initial non-renewable resource the resource is depleted. In both cases, for $R(0)=1$, and $R(0)=0.5$, figures 3 and 4 , the cumulative emission is slowly built up.

This is however different for a larger amount of initially available non-renewable energy. This case is demonstrated in figure 5. The next example thus shows the solution paths for the initial condition $R(0)=5$. 


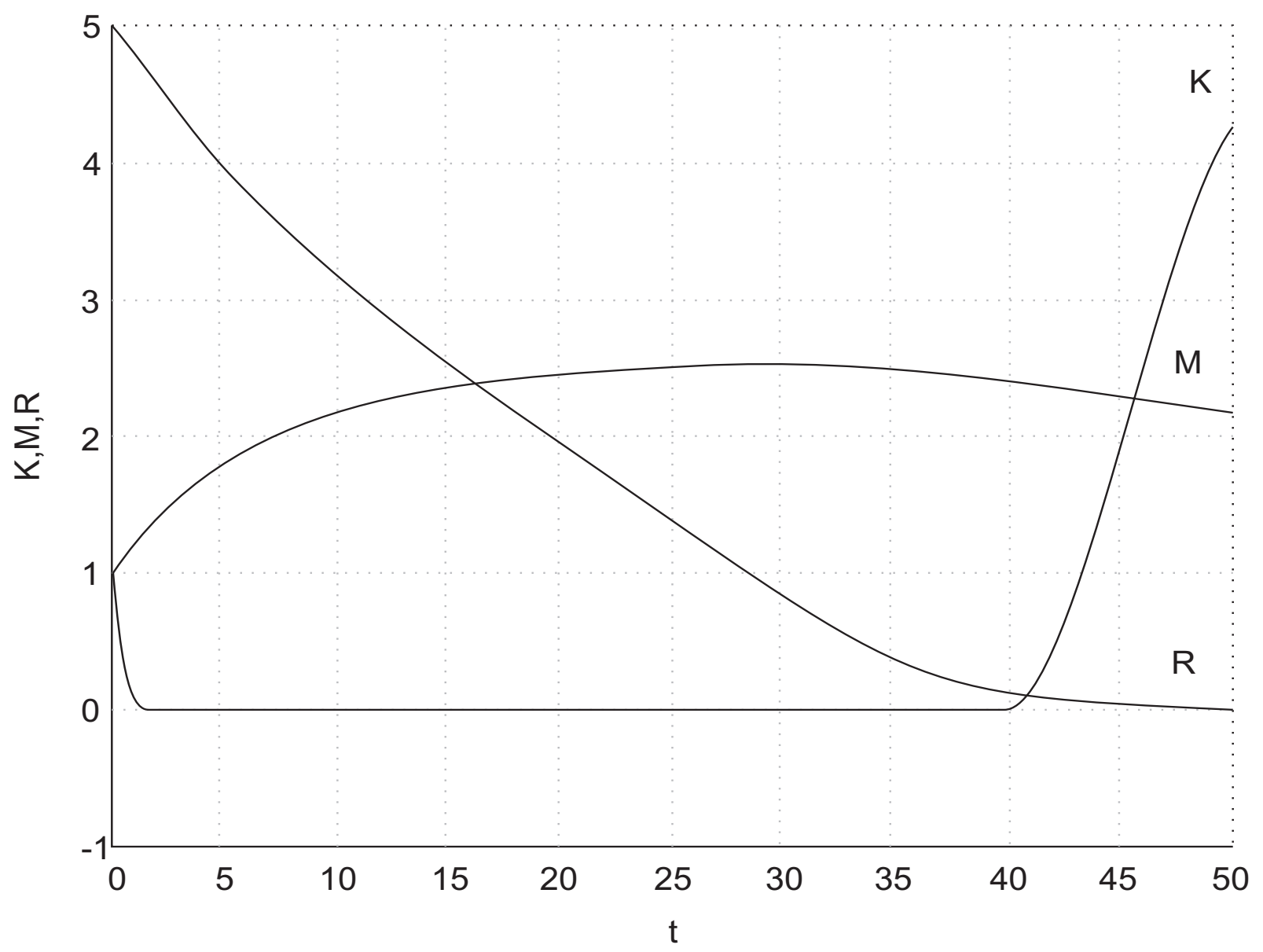

Figure 5: NMPC results for $R(0)=5, K(0)=1, M(0)=1, N=8$

In the case of figure 5 , if there is an initial large deposit of non-renewable energy $-R(0)=5$ - but the initial capital stock to produce renewable energy is relatively low, the high deposits of fossil energy will be quickly extracted 8 but the resource will not be depleted for a long time period. Here non-renewable energy, emitting $\mathrm{CO}_{2}$, will increase the totally emitted $\mathrm{CO}_{2}$ faster but non-renewable energy will be left unextracted for a prolonged time period. As can be observed - compare figures 4 and 5 - at time period 25, the cumulative emission of $\mathrm{CO}_{2}$ is higher, in figure 5 now with a larger initial deposit of the fossil resource, $R(0)=5$.

In figure 5 the cumulative emission of $\mathrm{CO}_{2}$ goes up to roughly 2.6, stays there for a long time period and then slowly decreases toward its steady state value of 2 . Thus, there will be greater concentration of $\mathrm{CO}_{2}$ piled up which also rises faster and stays higher for a larger $R(0)$, see the

\footnotetext{
${ }^{8}$ The numerical solutions showed that the extraction rates are high and stay persistently high.
} 
middle graph of figure 5 , as compared in figures 3 and 49 One can observe, if fossil energy is relatively abundant as compared to capital stock producing renewable energy, it is apparently optimal to delay the build-up of capital for a long time period. Note that the capital stock starts building up only after period 4010

The next example is for different initial conditions, $R(0)=0.5, R(0)=2.5$, but in both cases we assume a high initial capital stock $K(0)=3$. Yet, in both cases we also assume $M(0)=1$.

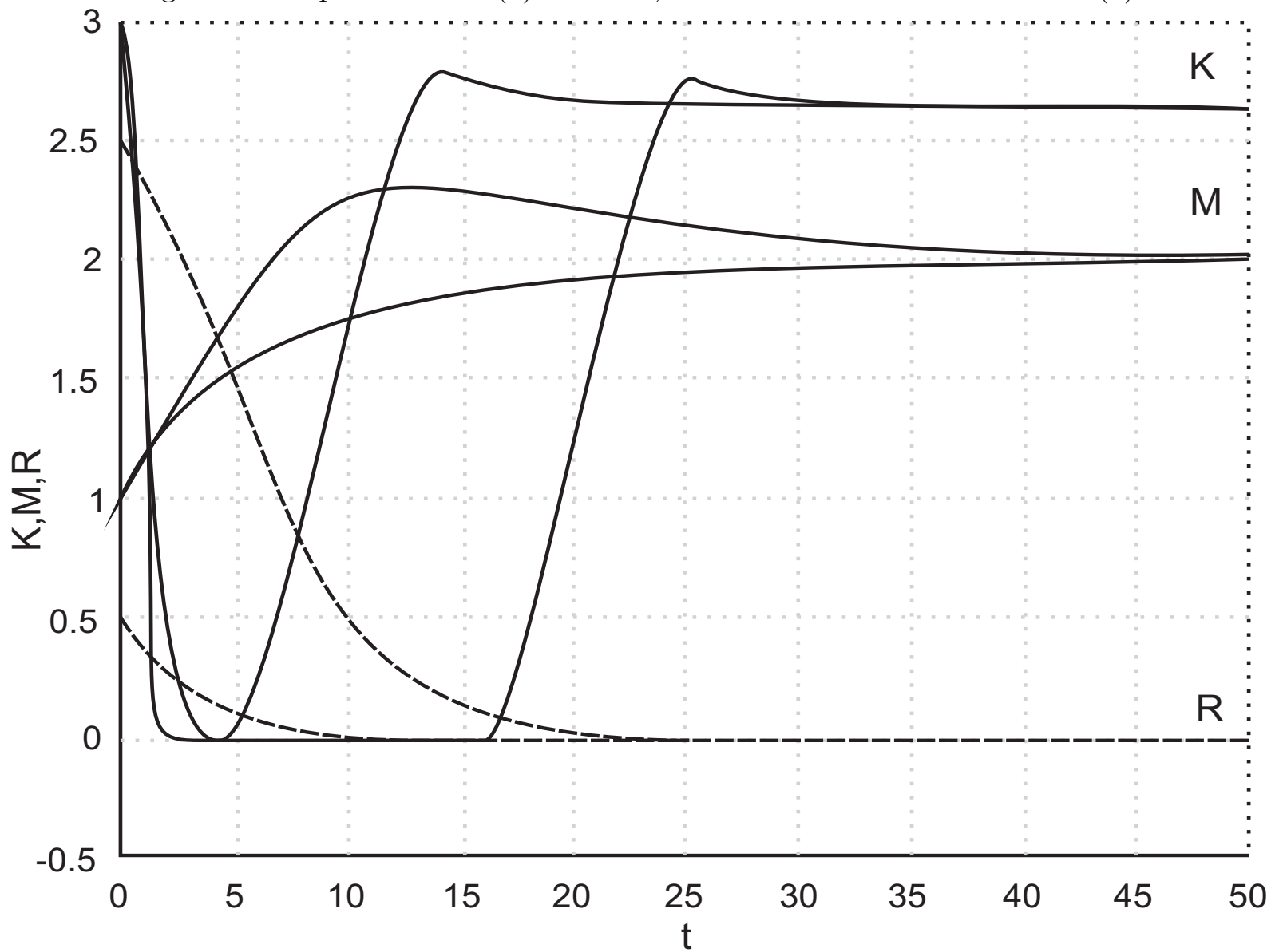

Figure 6: NMPC results for $R(0)=0.5$, and $R(0)=2.5$, and in both cases $K(0)=3, M(0)=$ $1, N=8$

In figure 6 , for the cases of a low $R(0)=0.5$ and high $R(0)=2.5$, we assume the same

${ }^{9}$ If we had computed the earth temperature as a result of the high cumulative $\mathrm{CO}_{2}$ emission, as done in Greiner et al. (2010), we would have observed higher temperature in the case of figure 5 as compared to figures 3 and 4 . This would hold also for figure 6 , for the case of a high initial $R$.

${ }^{10}$ This might lead countries with large initial deposits of $R$ not to build up renewable energy quickly. 
initial capital stock $K(0)=3$, and the same $M(0)=1$. As we can observe the different initial conditions for $R$, the non-renewable energy source, give different results over time. First, the high $R(0)=2.5$, significantly delays the optimal building up of capital stock - it starts being built up in period 15 instead of 5 , as for the low initial $R$. So it is for a prolonged period optimal to have a very low capital stock, and thus little renewable energy built up. Second, however, cumulative $\mathrm{CO}_{2}$ emission that goes with it, is significantly higher on the transition path, and welfare presumable significantly lower, as compared to the case of a high capital stock and a low initial non-renewable energy source $R$. 11

Next we will use a larger deposit of the non-renewable resource, $R(0)=5$, but also greater time horizon in our numerical procedure by employing $N=20$. As numerical studies with the NMPC method have shown, with a larger $N$ this might move the solution path closer to the steady state value of the model 12

\footnotetext{
${ }^{11}$ So, in general, two countries with the same initial capital stock, but different initial $R$ will contribute differently to the global creation of $\mathrm{CO}_{2}$.

${ }^{12}$ Experiments with the time horizon $N$, affecting the solution path in the neighborhood of the steady state (the turnpike properties of the solution) can be found in Gruene and Pannek (2012).
} 


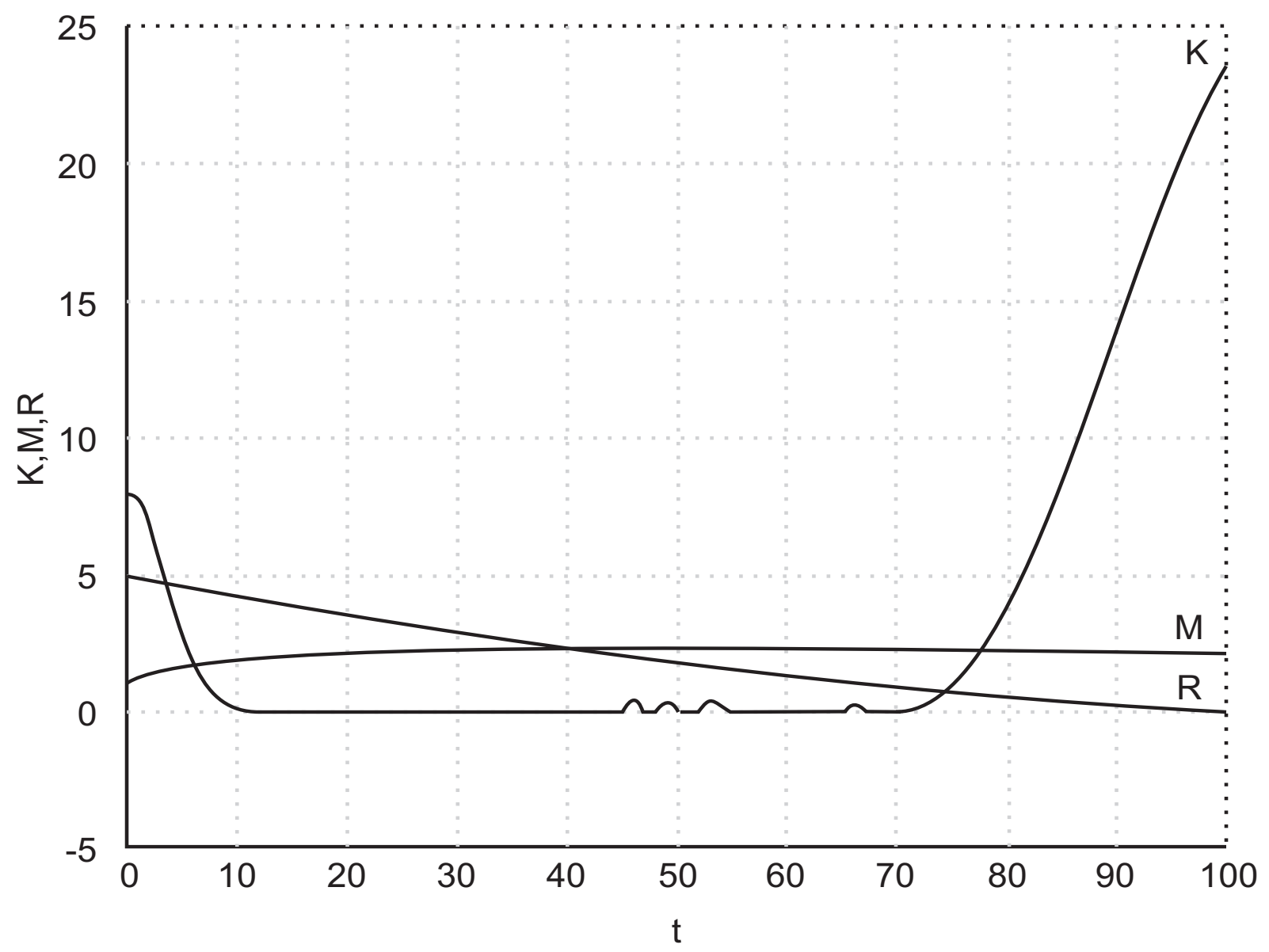

Figure 7: NMPC results for $R(0)=5, K(0)=8, M(0)=1, N=20$

As can be observed from the solution paths $R(0)=5, K(0)=8, M(0)=1, N=20$, not only the non renewable energy resource, and the cumulative $\mathrm{CO}_{2}$ emission go toward their steady state but also the capital stock. Note also that the cumulative $\mathrm{CO}_{2}$ emission rises first above 2 , its steady state value, but then declines. The rise above its steady state comes from the fact that the initial non-renewable energy resource is large and extracted slowly. The capital stock is declining first, and then later rising, as in figures 5 and 6 . So, it is optimal to use a low capital stock for a prolonged period of time but much non-renewable energy, before renewable energy is phased in.

For a final exercise we use a very small efficiency parameter for the renewable energy. We now take $A_{p}=1$. 


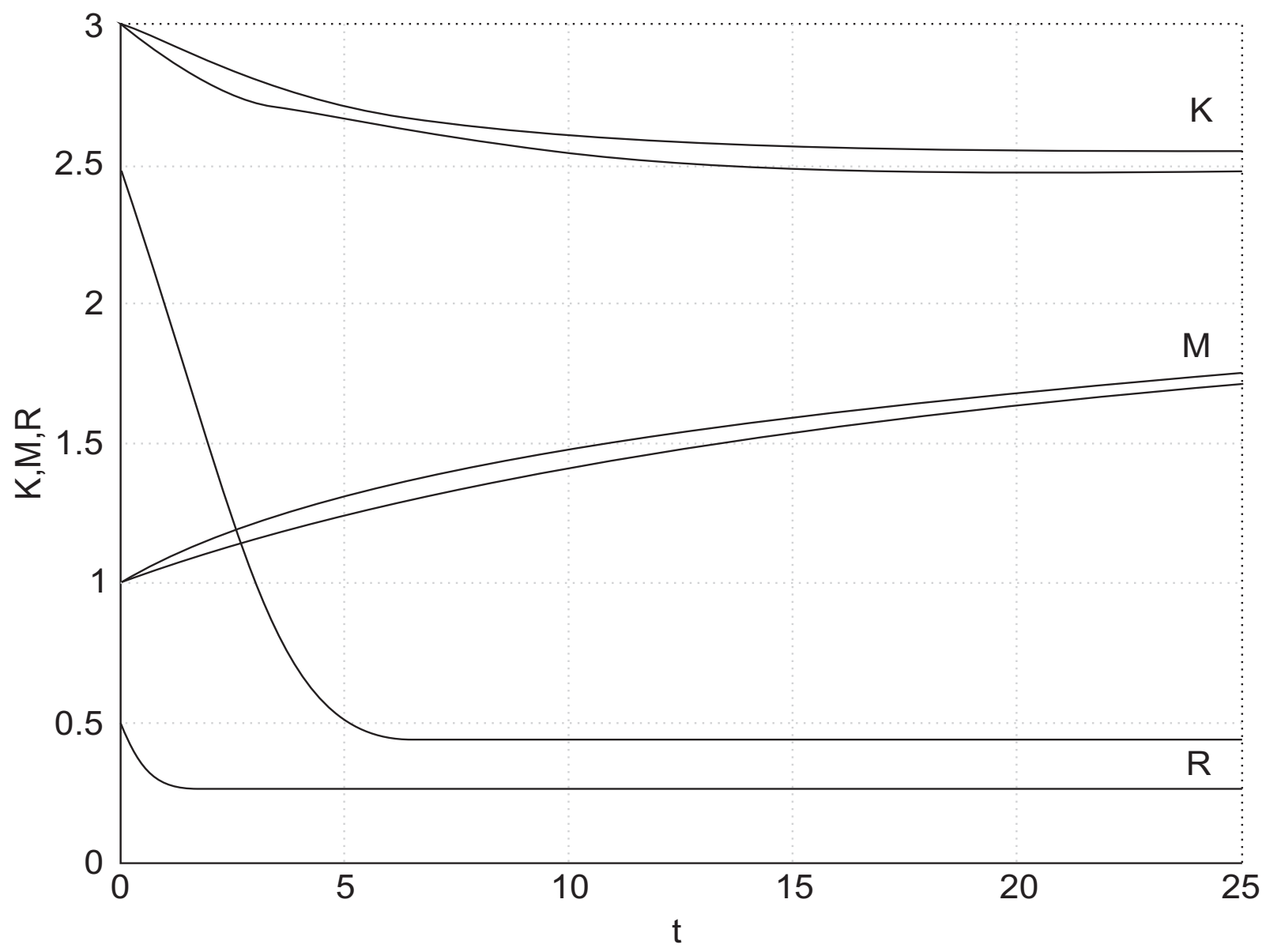

Figure 8: NMPC results for $R(0)=2.5$, and $R(0)=0.5$, and in both cases $K(0)=3, M(0)=$ $1, A_{p}=1, N=8$

In the case of figure 8, with $R(0)=2.5$, and $R(0)=0.5$, and in both cases $K(0)=3, M(0)=$ 1 , but $A_{p}=1$, we can observe that the non-renewable energy use steadily declines but for both initial conditions for $R$ non-renewable energy is left unextracted (see the trajectories going below 0.5 but above 0 ). Here then the cumulative $\mathrm{CO}_{2}$ emission is lower than in the cases of figures 5-7, where all non-renewable resource is completely depleted. So if there is a high capital stock to accelerate the use of renewable energy or a low stock of deposits of non-renewables, the more non-renewables are left unextracted and the cumulative $\mathrm{CO}_{2}$ emission is lower the lower the initial $R(0)$ is.

This suggests that one might want to constrain one-self to the lower initial $R(0)=0.5$ 
which generates less cumulative externalities for 13 Hence, if we have less initial deposits in nonrenewable energy $(R(0)=0.5$ as compared to $R(0)=2.5$ in figure 8$)$, the existence of a higher capital stock, and thus the production of renewable energy, will phase in renewable energy faster and this could reduce the use of non-renewable energy. Note that we have not computed the welfare function in all of our cases using NMPC. This can be done by employment DP.

\section{Conclusions}

In this paper we have studied the issue of global warming and the transition from non-renewable to renewable energy in a canonical growth model with negative externalities that affect household' s preferences. We have two decision variables, consumption and extraction rate of the non-renewable resource, and three state variables - capital stock, non-renewable resource and cumulative $\mathrm{CO}_{2}$ emission, the latter affecting welfare of households.

We have analyzed how renewable energy sources can be phased in, in a model for a socially optimal solution and in a laissez-faire economy. In the long-run the two versions are equivalent, unless the rates of time preference differ, but transitional dynamics are not identical. We derived the optimal tax rate (and lump-sum subsidy) for the case of a laissez-faire economy such that the laissez-faire economy coincides with the social optimum. We have also seen that optimal subsidies are zero if the social discount rate coincides with that of agents in the laissez-faire economy. Only if the discount rate of the social planner's problem exceeds that of agents in the laissez-faire economy, a subsidy for renewable energy should be paid besides levying a tax on non-renewables.

In the numerical part of the paper, which uses DP and NMPC, we have studied the dynamics of phasing out of the fossil energy source and the phasing in of renewable energy, both depending on the initial level of $R(0)$ and $K(0)$. Whereas DP gives us a global solution, NMPC provides single solution paths only. Using NMPC we have explored how the extraction rates $u$ and the capital stock to produce renewable energy $K$ evolve over time, and whether the initial

\footnotetext{
${ }^{13}$ This result seems to be particularly important if there are increasing costs involved in discovering new deposits and adding them to the known deposits, as studied in Greiner et al. (2012). In our cases studied here the extraction cost is linear and we have no discovery cost.
} 
levels and paths of the non-renewable energy and the capital stock are relevant for the level of the cumulative $\mathrm{CO}_{2}$ emission, and thus global warming. In particular the NMPC allowed us important insight into the dynamics of the transition process from non-renewable to renewable energy - and when the backstop technology is phased in.

If the available non-renewable energy resource is initially high, the extraction rate of the nonrenewable resource is first high and then continuously declining, and it appears to be optimal to have for a long time period a low or even zero capital stock to produce the renewable energy. Yet, this keeps the $\mathrm{CO}_{2}$ emission high, ending up with a high level of $\mathrm{CO}_{2}$ concentration sooner. Thus, countries with high non-renewable energy sources naturally will delay the build up of capital stock to produce renewable energy and the delay will be the larger the higher the initial stock of the non-renewable energy source is. With a high initial non-renewable resource stock we could even observe an overshooting of cumulated $\mathrm{CO}_{2}$ emission over its long-run steady state value. In this case, extraction is so large that it transitorily exceeds its long-run value before it begins to decline and converge to its steady state.

Further, for low efficiency in non-renewable energy production we have seen that it can be optimal to leave some of the non-renewable energy resource unextracted. In this case it is optimal to switch completely to renewable energy production before the resource is used up. We also saw that the resource left in situ is the larger the higher the initial value of the stock of the non-renewable resource.

In future research our model could be extended in several directions. For example, it seems reasonable to allow for increasing costs involved in discovering new deposits that increase the known deposits, as studied in Greiner et al. (2012). In our cases studied here the extraction cost is linear and we have not introduced non-linear discovery cost. Further research along those lines as well as on the difference between social and private rate of discounting is needed. 


\section{Appendix}

\section{Proof of proposition 1}

Setting $\rho_{k}=\rho$ and $\theta=\tau=\Gamma=0$ immediately shows that for $u=0$ the steady state values of the social optimum and of the competitive market economy are the same. Further, it is easily seen that $K^{\star}$ as well as $C^{\star}$ negatively depend on $\rho$.

\section{Proof of proposition 2}

To prove proposition 2 we first set $\rho_{k}=\rho$ and note that $\dot{\lambda}_{1}=\dot{\gamma}_{1}$ immediately shows that $\theta=0$ must hold. Further, we know that the optimal extraction rate in the social optimum must be equal to that in the competitive market economy. Setting (14) $=(23)$ and using $\theta=0$ gives $\tau=-\lambda_{3} \beta_{1} / \lambda_{1}$. These two conditions guarantee that the extraction of the non-renewable resource, consumption and the GHG concentration in the social optimum and in the competitive market economy coincide. Finally, $\Gamma$ has to be set such the evolution of the capital stock in the two versions is the same. Setting $A\left(A_{p} u+A_{n} K\right)^{\alpha}-C-a u-\delta K=A\left(A_{p} u+A_{n} K\right)^{\alpha}-C-(a-$ $\left.\lambda_{3} \beta_{1} / \lambda_{1}\right) u-\delta K-\Gamma$ and solving with respect to $\Gamma$ gives the result in the proposition.

\section{Proof of proposition 3}

Now, we have $\rho_{k}>\rho$. Again, we know that $\dot{\lambda}_{1}=\dot{\gamma}_{1}$ must hold. Setting $(15)=(24)$ and solving the resulting equation with respect to $\theta$ yields $\theta=\Delta \rho /\left(\Delta \rho+Y_{K}\right)$. Next, equating optimal extraction rates and solving for $\tau$ leads to $\tau=\theta\left(\lambda_{2} / \lambda_{1}\right)-\lambda_{3} \beta_{1} / \lambda_{1}$, with $\theta=\Delta \rho /\left(\Delta \rho+Y_{K}\right)$. Finally, $\Gamma$ is found by setting equal investment in the social optimum to investment in the competitive market economy: $\left.A\left(A_{p} u+A_{n} K\right)^{\alpha}-C-a u-\delta K=A\left(A_{p} u+A_{n} K\right)^{\alpha}-C-(a+\tau) u-\delta K-\Gamma\right) /(1-\theta)$. Solving for $\Gamma$ gives the result.

\section{References}

[1] Adili, Degaulle (2012) "Developing countries economic growth with non-renewable energy source endowment." manuscript, New School for Social Research, New York, mimeo. 
[2] Angeli, David, Rishi Amrit, James R. Rawlings (2012) "On average performance and stability of economic model predictive control." IEEE Transactions on Automatic Control, to appear, IEEE early access: DOI 10.1109/TAC.2011.2179349

[3] Arrow, Kenneth J., Mordecai Kurz (1970) Public Investment, the Rate of Return, and Optimal Fiscal Policy. The John Hopkins Press, Baltimore.

[4] Brechet, Thierry, Carmen Carmacho, und Vladimir M. Veliov (2012) "Adaptive ModelPredictive Climate Policies in a Multi-Country Setting." Research Report 2012-02, University of Technology, Vienna.

[5] Byrne, Margaret M. (1997) "Is Growth a Dirty Word? Pollution, Abatement and Endogenous Growth." Journal of Development Economics, 54, 261-84.

[6] Edenhofer, Ottmar, Kai Lessmann, Claudia Kemfert, Michael Grubb, Jonathan Kohler (2006) "Induced technological change: Exploring its implications for the economics of atmospheric stabilization: Synthesis report from the innovation modeling omparison project." The Energy Journal, 27, 57-108.

[7] Greiner, Alfred (2011) "Environmental pollution, the public sector and economic growth: A comparison of different scenarios." Optimal Control Applications \& Methods, 32, 527-44.

[8] Greiner, Alfred, Willi Semmler, Tobias Mette (2012) "An economic model of oil exploration and extraction." Computational Economics, 40, 387-99.

[9] Greiner, Alfred, Lars Gruene, Willi Semmler (2010) "Growth and climate change: Threshold and multiple equilibria." In: J. Crespo Cuaresma, T. Palokangas and A. Tarasyev (eds.) Dynamic Systems, Economic Growth, and the Environment: 63-78. Springer, Berlin.

[10] Gruene, Lars (2013) "Economic receding horizon control without terminal constraints", Automatica, 49, 725-34.

[11] Gruene, Lars, Jürgen Pannek (2011) Nonlinear Model Predictive Control-Theory and Algorithms. Springer Verlag, London. 
[12] Gruene, Lars, Willi Semmler (2004), "Using dynamic programming with adaptive grid scheme for optimal control problems in economics", Journal of Economic Dynamics and Control, 28, 2427-56.

[13] Heinzel, Christoph, Ralph Winkler (2011) "Distorted Time Preferences and Time-to-Build in the Transition to a Low-Carbon Energy Industry." Environmental and Resource Economics, 49, 217-41.

[14] Hoel, Michael, Snorre Kverndokk (1996) "Depletion of fossil fuels and the impacts of global warming." Resource and Energy Economics, 18, 115-136.

[15] Jacobson, Mark Z., Mark A. Delucchi, (2011) "Providing all global energy with wind, water, and solar power, Part I: Technologies, energy resources, quantities and areas of infrastructure, and materials." Energy Policy, 39, 1154-69.

[16] Jacobson, Mark Z., Mark A. Delucchi, (2011a) "Providing all global energy with wind, water, and solar power, Part II: Reliability, system and transmission costs, and policies." Energy Policy, 39, 1170-90.

[17] Krautkraemer, Jeffrey A. (1985) "Optimal growth, resource amenities and the preservation of natural environments." Review of Economic Studies, 52, 153-70.

[18] Krautkraemer, Jeffrey A. (1998) "Nonrenewable resource scarcity." Journal of Economic Literature, 36, 2065-107.

[19] Maurer, Helmut, Willi Semmler (2010), "An optimal control model of oil discovery and extraction." Applied Mathematics and Computation, 217, 1163-69.

[20] Mittnik, Stefan, Mika Kato, Daniel Samaan, Willi Semmler (2010) "Climate policies and structural change - employment and output effects of sustainable growth." Working Paper, The New School for Social Research, Comparative Empirical Macroeconomics, New York, January 28, 2010.

[21] Nordhaus, William D. (2008) A Question of Balance. Weighing the Options on Global Warming Policies. Yale University Press, New Haven. 
[22] Smulders, Sjak, Raymond Gradus (1996) "Pollution abatement and long-term growth." European Journal of Political Economy, 12, 505-32.

[23] van der Ploeg, Frederic, Cees Withagen (2011) "Growth, renewables and the optimal carbon tax." OxCarre Research Paper 55, University of Oxford, Oxford.

[24] van der Ploeg, Frederic, Cees Withagen (2012) "Too much coal, too few oil." Journal of Public Economics, 96, 62-77. 